\section{Macular Edema and Silicone Oil Tamponade}

Claudio Azzolini ${ }^{1 *}$, Simone Donati ${ }^{1}$, Simona Maria Caprani ${ }^{1}$, Carlo Gandolfi ${ }^{1}$, Riccardo Vinciguerra ${ }^{1}$, Francesco Semeraro ${ }^{2}$, Mario R. Romano ${ }^{3}$, Luigi Bartalena $^{4}$ and Cesare Mariott ${ }^{5}$

${ }^{1}$ Department of Surgical and Morphological Sciences, Section of Ophthalmology, School of Medicine, University of Insubria, Ospedale di Circolo, Varese, Italy

${ }^{2}$ Eye Clinic, Department of Neurological Sciences and Vision, University of Brescia, Brescia, Italy

${ }^{3}$ Department of Ophthalmology, Istituto Clinico Humanitas, Milan, Italy

${ }^{4}$ Department of Clinical and Experimental Medicine, Endocrine Unit, University of Insubria, Ospedale di Circolo, Varese, Italy

${ }^{5}$ Department of Ophthalmology, Polytechnic University of Ancona, Ancona, Italy

*Corresponding author: Claudio Azzolini MD, Department of Surgical and Morphological Sciences - Section of Ophthalmology, School of Medicine-University of Insubria, Via Guicciardini 9, 21100 Varese, Italy, Tel: 0039 0332278217; E-mail: claudio.azzolini@uninsubria.it

Received date: Aug 26, 2014, Accepted date: Oct 30, 2014, Published date: Nov 4, 2014

Copyright: (C) 2014 Azzolini C, et al. This is an open-access article distributed under the terms of the Creative Commons Attribution License, which permits unrestricted use, distribution, and reproduction in any medium, provided the original author and source are credited.

\section{Abstract}

Purpose: To analyze the risk factors for inflammatory macular edema (ME) in a series of patients undergoing vitreoretinal surgery using Silicone Oil (SO) as a long-term tamponade.

Materials and methods: We examined 118 consecutive eyes of 115 patients, mean age 57.8 years (range 39-79), suffering from various types of severe retinal detachment. Surgical procedures were carried out on all patients, and SO $1000 \mathrm{cs}$ was injected into the eye at the end of surgery to permit stable retinal reattachment. ME was classified as initial, medium and severe. The characteristics of ME were compared with various preoperative, intra-surgical and postoperative parameters. Statistical analyses were carried out using the $\mathrm{T}$ test and the Pearson correlation coefficient.

Results: Twenty-six eyes were excluded. Twenty out of 92 eyes (22\%) presented various types of ME. No significant correlation was found between $\mathrm{ME}$ and age or complication and duration of surgery. Significant correlation was found between ME and macular status before surgery and time length of intraocular permanence of SO.

Conclusion: SO should be removed as soon as possible, in particular when the preoperative macular status is compromised. Decreased molecular transport in the vitreous space, permanence of inflammatory substances between SO and the macula, mechanical floating of SO and dangerous light exposure might be involved in the pathogenesis of ME.

Keywords: Silicone oil; Macular edema; OCT imaging; Retinal detachment

\section{Introduction}

Macular edema (ME) is the swelling of soft retinal tissue due to an abnormal accumulation of fluid. It may be cytotoxic in origin, with swelling within cells, or more frequently it can be vasogenic, with water accumulation between cells [1-4].

Clinically, ME types are characterized by intraretinal cysts of differing number and size. On OCT imaging, intraretinal cysts are seen as well delimited hyporeflective areas on the retinal tissue that determine an increase of macular thickness. OCT software measures macular thickness in $\mu \mathrm{m}[5,6]$ and recent software may also evaluate the intramacular number and extension of intraretinal hyporeflective spaces in $\mu \mathrm{m}^{2}$ [7]. As the major cause of visual loss in many retinal diseases, ME should be identified at diagnosis and monitored during follow-up to assess the degree of functional impairment and the effects of any treatment carried out.

Silicone oil (SO) is widely used in vitreoretinal surgery [8-11]. It is injected into the eye in difficult cases of retinal detachment at the end of surgery as a long-term intravitreal tamponade to permit stable reattachment of the retina. However, the known complications of silicone oil are many, and need to be recognized by the surgeon. The most frequent problems are: intraconjunctival oil inclusion cysts, band keratopathy, and cataract and glaucoma [12-15]. SO droplets may reach the brain through the optic nerve [16]. SO may also have toxic effects on the optic nerve and the retina like ME $[17,18]$. After SO removal, transient hypotony, sudden visual loss, macular microstructure alteration, thinning of the retina and other complications has been described [17-25]. Almost all of these complications are responsible for progressive visual deterioration.

The aim of our study was to analyze the presence, type, duration of $\mathrm{ME}$, and to analyze the risk factors of $\mathrm{ME}$ in a series of patients undergoing vitreoretinal surgery using $\mathrm{SO}$ as a long-term tamponade.

\section{Materials and Methods}

The present study was designed as an observational prospective analysis of a consecutive case series. We examined 118 consecutive eyes of 115 patients (61 men and 54 women), mean age 57.8 years old (range 39-79), suffering from severe retinal detachment who were referred to the Ophthalmology Clinic, Department of Surgical and 
Morphological Sciences, University of Insubria, Varese from June 2011 to April 2013. Patients with various types of retinal detachment with macula on or off were included in the study: proliferative vitreoretinopathy, giant retinal tear, and traumatic retinal detachment. Exclusion criteria were myopia $>6$ diopters, any type of previous macular treatment (photocoagulation, surgery, intravitreal steroids and/or anti-VEGF therapy), and vascular retinopathy (vein or arterial occlusion, diabetic retinopathy).

The same surgeon (CA) operated on all patients using a 20-23 gauge technique and standard intraocular instruments. Total vitrectomy, including accurate vitreous base removal with vitrectome (Stellaris, Bausch and Lomb, Rochester, New York, USA) at surgical microscope (OPMI 1, Carl Zeiss, Jena, Germany) was carried out. When considered necessary, specific retinal surgical steps were performed: peeling, delamination and segmentation of the anterior/ posterior membrane, complete removal of all residual epiretinal tissue, retinectomies, use of liquid perfluorocarbon and endophotocoagulation. At the end of surgery, silicone oil $1000 \mathrm{cs}$ (Micromed srl, Roma, Italy) was injected into the eye through BSS-SO or liquid perfluorocarbon-SO exchange. Upon termination of surgery each quadrant of the retina was flat.

During surgery, all known procedures to avoid surgery-induced macular damage were used, such as low light intensity, light beam kept focused on the fovea for the minimum time necessary, reduced macula manipulation, and limited duration of surgical procedures. Cataract surgery, if necessary, was performed only after silicone-oil removal on a different session. All patients gave written informed consent ("Ospedale di Circolo", Varese, Italy). The study satisfied the tenets of the Declaration of Helsinki.

Patients were examined at baseline and at month 1 after surgery with SO injection, then at month 1 and 6 after the removal of silicone oil. Functional outcomes were assessed with Best Corrected Visual Acuity (BCVA) in LogMAR. Complete ophthalmological examination was carried out at baseline and at each follow-up visit. A Spectral Domain OCT (OCT/SLO OTI, Toronto, Canada) study was performed to evaluate macular status and thickness. Central foveal thickness was measured using a high-resolution topographic map automated protocol. An expert operator (SD) carried out manual caliper evaluation when OCT software encountered artifacts causing measurement bias.

Various types of ME were observed. ME was defined as macular thickening with the presence of hyporeflective intraretinal spaces. We classified macular edema after SD OCT examination as following: initial (macular thickness $<350 \mu \mathrm{m}$ and presence of intraretinal hyporeflective areas of different shapes), mild $(350-450 \mu \mathrm{m})$, and severe $(>450 \mu \mathrm{m})$. In addition, each feature could be worsened by a cystoid aspect and the presence of subfoveal neuroepithelial detachment (Figure 1). The qualitative and quantitative characteristics of macular edema were compared and correlated with various preoperative, intrasurgical and postoperative parameters.
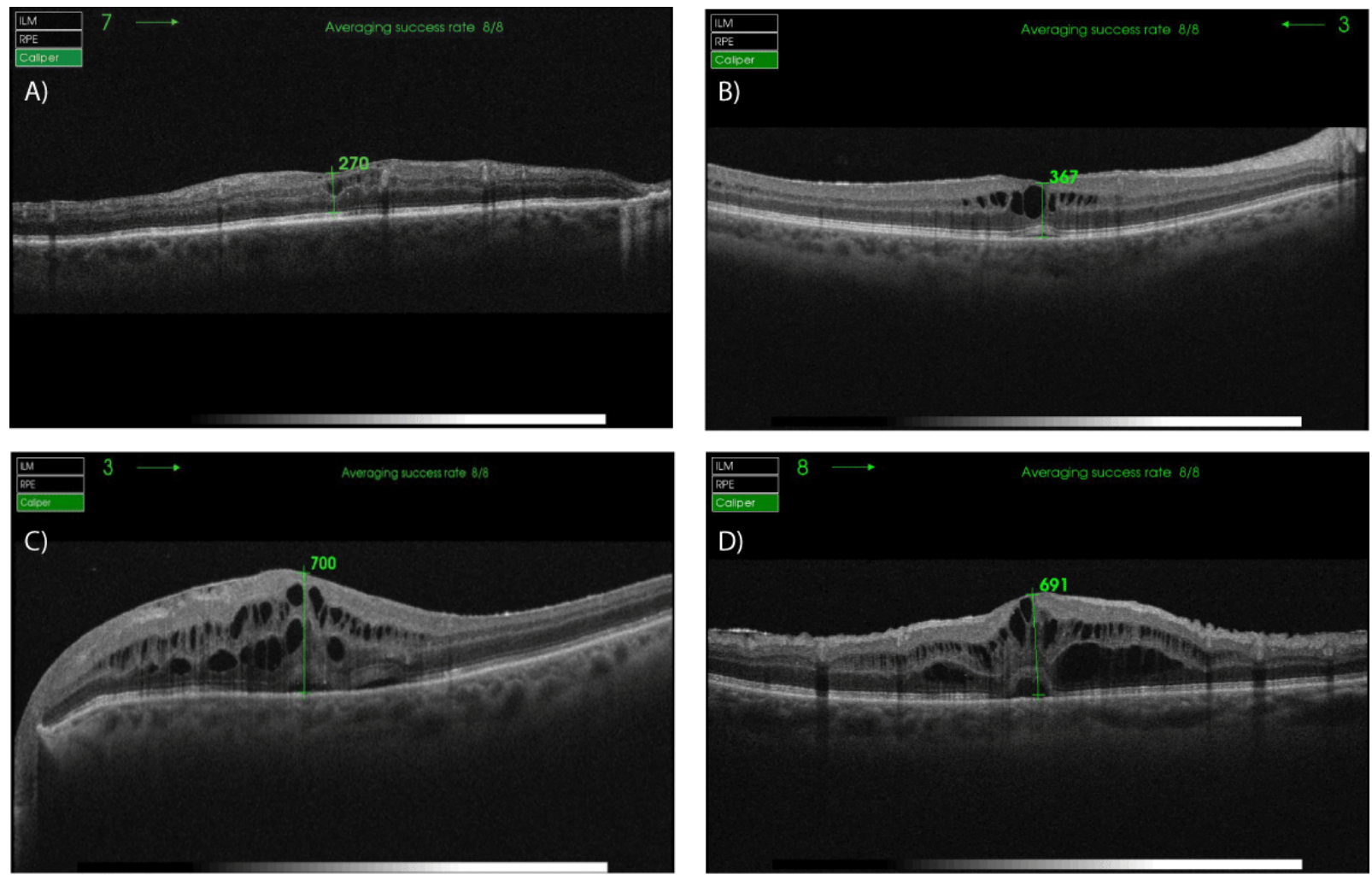

Figure 1: Type of macular edema; a) initial (macular thickness $<350 \mu \mathrm{m})$; b) mild $(350-450 \mu \mathrm{m})$; c) severe $(>450 \mu \mathrm{m})$; d) severe macular edema (macular thickness $>450 \mu \mathrm{m}$ ) worsened by cystoid aspect and subfoveal neuroepithelial detachment. 
Standard methods of descriptive statistics were used to analyze collected data: the $\mathrm{T}$ student test and the $\mathrm{CHI}$ squared test were applied to verify statistical significance $(\mathrm{p}<0.05)$. A Pearson Coefficient was applied to test correlation between dependent and independent variables.

\section{Results}

\begin{tabular}{|c|c|c|c|c|c|c|}
\hline$n^{\circ}$ & Age & Sex & $\begin{array}{l}\text { VA } \\
\text { Baseline }\end{array}$ & $\begin{array}{l}\text { Presence of Symptoms } \\
\text { (Days before } \\
\text { Baseline Visit) }\end{array}$ & $\begin{array}{l}\text { Type of RD } \\
\text { Macula Off/On }\end{array}$ & $\begin{array}{l}\text { MT } \\
\text { Baseline }\end{array}$ \\
\hline 1 & 48 & $M$ & 0.40 & 10 & ON & 230 \\
\hline 2 & 74 & $\mathrm{~F}$ & 0.05 & 5 & ON & 256 \\
\hline 3 & 49 & $\mathrm{M}$ & 0.40 & 15 & ON & 256 \\
\hline 4 & 80 & $\mathrm{M}$ & 1.50 & 20 & OFF & nd \\
\hline 5 & 82 & $\mathrm{M}$ & 0.70 & 7 & ON & 243 \\
\hline 6 & 50 & M & 0.50 & 30 & ON & 254 \\
\hline 7 & 44 & M & 1.50 & 25 & OFF & nd \\
\hline 8 & 61 & $\mathrm{~F}$ & 1.20 & 45 & OFF & nd \\
\hline 9 & 46 & $\mathrm{~F}$ & 1.00 & 20 & OFF & nd \\
\hline 10 & 57 & $F$ & 0.70 & 10 & OFF & nd \\
\hline 11 & 52 & M & 0.30 & 12 & ON & nd \\
\hline 12 & 69 & M & 0.40 & 10 & ON & nd \\
\hline 13 & 55 & $F$ & 1.50 & 10 & OFF & nd \\
\hline 14 & 45 & M & 1.50 & 7 & OFF & nd \\
\hline 15 & 42 & $\mathrm{~F}$ & 0.70 & 7 & ON & 245 \\
\hline 16 & 67 & M & 1.70 & 30 & OFF & nd \\
\hline 17 & 68 & $F$ & 1.20 & 5 & OFF & nd \\
\hline 18 & 43 & M & 0.70 & 2 & ON & 221 \\
\hline 19 & 48 & M & 0.40 & 1 & ON & 210 \\
\hline 20 & 45 & M & 0.30 & 8 & ON & nd \\
\hline Mean & 56.33 & & 0.83 & 13.95 & & 239.38 \\
\hline SD & 12.74 & & 0.51 & 11.22 & & 17.32 \\
\hline
\end{tabular}

Table 1: Preoperative data of the 20 out of 92 enrolled eyes. VA: LogMAR Visual Acuity; RD: Retinal Detachment, MT: Macular Thickness; nd: Not Determined; SD: Standard Deviation.

Table 2 shows all considered clinical and surgical parameters: visual acuity, type of edema, and macular thickness as well as duration of surgery, surgical variables, and SO intraocular permanence.

Table 3 shows the different behavior of the studied variables between patients with macular edema and patients without macular
Twenty-six cases were excluded from the study as they needed additional surgery for PVR, retinal detachment recurrence, or vitreous opacity after SO removal.

In 20 out of the 92 eyes (22\%) remaining in the study we diagnosed various types of ME. Patient demographic data are summarized in Table 1. 
Citation: Azzolini C, Donati S, Caprani SM, Gandolfi C, Vinciguerra R, et al. (2014) Macular Edema and Silicone Oil Tamponade. J Clin Exp

Page 4 of 8

\begin{tabular}{|c|c|c|c|c|c|c|c|c|c|c|c|c|c|}
\hline$n^{\circ}$ & $\begin{array}{l}\text { Time duration } \\
\text { of intraocular } \\
\text { surgical } \\
\text { procedures } \\
\text { (minutes) }\end{array}$ & $\begin{array}{l}\text { Surgica } \\
\text { Variables }\end{array}$ & $\begin{array}{l}\text { VA } 1 \\
\text { month } \\
\text { with } \\
\text { so }\end{array}$ & $\begin{array}{l}\text { Type of } \\
\text { edema }\end{array}$ & $\begin{array}{l}\text { MT } 1 \\
\text { month } \\
\text { with } \\
\text { so }\end{array}$ & \begin{tabular}{|l|} 
Mean \\
Time of \\
so \\
presence \\
(months)
\end{tabular} & $\begin{array}{l}\text { VA } 1 \\
\text { month } \\
\text { post So } \\
\text { removal }\end{array}$ & $\begin{array}{l}\text { Type of } \\
\text { edema }\end{array}$ & $\begin{array}{l}\text { MT } 1 \\
\text { month } \\
\text { post so } \\
\text { removal }\end{array}$ & $\begin{array}{l}\text { VA } 6 \\
\text { month } \\
\text { post So } \\
\text { removal }\end{array}$ & $\begin{array}{l}\text { Type of } \\
\text { edema }\end{array}$ & $\begin{array}{l}\text { MT } 6 \text { month } \\
\text { post SO } \\
\text { removal }\end{array}$ & $\begin{array}{l}\text { Therapy } \\
\text { applied }\end{array}$ \\
\hline 1 & 54 & no & 0.4 & 1 & 312 & 2.8 & 0.3 & 2 & 356 & 0.2 & 1 & 330 & 1 \\
\hline 2 & 45 & no & 0.3 & 1 & 261 & 2.4 & 0.2 & 2 & 356 & 0.2 & 1 & 310 & 1 \\
\hline 3 & 47 & no & 0.9 & 2 & 365 & 2.5 & 0.7 & 2 & 380 & 0.3 & 1 & 282 & 1 \\
\hline 4 & 87 & yes & 0.9 & 2 & 390 & 2.6 & 0.9 & 3 & 480 & 0.5 & 1 & 240 & 3 \\
\hline 5 & 63 & yes & 0.7 & 1 & 300 & 2.7 & 0.6 & 2 & 420 & 0.3 & 1 & 310 & 4 \\
\hline 6 & 59 & yes & 0.4 & 1 & 284 & 2.8 & 0.5 & 2 & 376 & 0.4 & 1 & 240 & 3 \\
\hline 7 & 72 & yes & 1.5 & 2 & 380 & 4.8 & 1.2 & 3 & 480 & 0.5 & 1 & 312 & 2 \\
\hline 8 & 91 & yes & 1.2 & 1 & 332 & 4.5 & 0.9 & 3 & 510 & 0.3 & 1 & 290 & 1 \\
\hline 9 & 49 & no & 0.7 & 1 & 294 & 2.4 & 0.3 & 2 & 420 & 0.4 & 1 & 256 & 3 \\
\hline 10 & 45 & no & 0.9 & 1 & 253 & 3.2 & 0.5 & 2 & 410 & 0.5 & 2 & 350 & 2 \\
\hline 11 & 74 & yes & 0.4 & 2 & 375 & 3.8 & 0.3 & 1 & 370 & 0.25 & 1 & 320 & 3 \\
\hline 12 & 64 & yes & 0.4 & 1 & 295 & 2.1 & 0.3 & 1 & 312 & 0.3 & 1 & 290 & 2 \\
\hline 13 & 97 & yes & 0.9 & 3 & 490 & 3.4 & 0.45 & 2 & 420 & 0.4 & 1 & 280 & 2 \\
\hline 14 & 85 & yes & 0.9 & 1 & 320 & 3.1 & 0.35 & 2 & 354 & 0.5 & 1 & 345 & 2 \\
\hline 15 & 43 & no & 0.7 & 1 & 267 & 2.9 & 0.4 & 1 & 290 & 0.5 & 1 & 310 & 2 \\
\hline 16 & 64 & no & 1.2 & 2 & 358 & 3.6 & 0.7 & 2 & 390 & 0.9 & 1 & 252 & 3 \\
\hline 17 & 65 & yes & 1.2 & 3 & 450 & 3.3 & 0.7 & 2 & 430 & 0.9 & 2 & 400 & 4 \\
\hline 18 & 55 & no & 0.9 & 2 & 380 & 2.4 & 0.7 & 1 & 310 & 0.4 & 1 & 256 & 2 \\
\hline 19 & 45 & no & 1.2 & 1 & 310 & 3.7 & 1.5 & 2 & 350 & 0.7 & 1 & 230 & 2 \\
\hline 20 & 41 & no & 0.7 & 1 & 280 & 3.5 & 0.9 & 2 & 389 & 0.2 & 1 & 245 & 1 \\
\hline Mean & 62.25 & & 0.82 & & 334.80 & 3.13 & 0.62 & 1.95 & 390.15 & 0.43 & & 292.40 & \\
\hline SD & 17.27 & & 0.33 & & 63.12 & 0.71 & 0.34 & 0.60 & 57.90 & 0.21 & & 44.33 & \\
\hline
\end{tabular}

Table 2: Clinical Data summary for the macula edema studied patients. Surgical variables: difficult PVR removal, strong macular manipulation. VA: LogMAR Visual Acuity; Type of macular edema:- 0: Normal Macula; 1: Mild Edema <350 $\mu \mathrm{m}$ Thickness; 2: Medium Between $350-450 \mu \mathrm{m}$; 3: Severe $>450 \mu \mathrm{m}$. MT: Macular Thickness; Therapy: 1: Non-Steroidal Anti-Inflammatory Drug; 2: Topical Steroid; 3: Non-steroidal Antiinflammatory Drug and Topical Steroid; 4: Steroid Topic and Parabulbar Injection of Steroid.

\begin{tabular}{|l|l|l|l|}
\hline Summary Data & Non Macular edema & Macular edema & \\
\hline & Mean \pm SD & Mean \pm SD & P value \\
\hline Age & $59.41 \pm 13.5$ & $56.33 \pm 12.74$ & 0.35 \\
\hline Symptoms Duration (days) & $10.74 \pm 6.1$ & $13.95 \pm 11.22$ & 0.08 \\
\hline Macula Off & $21 \%$ & $45 \%$ & 0.02 \\
\hline Surgery Procedures Duration & $56.16 \pm 12.06$ & $62.25 \pm 17.27$ & 0.07 \\
\hline Intrasurgical Variables & $10 \%$ & $30 \%$ & nd \\
\hline So permanence (months) & $2.75 \pm 0.61$ & $3.13 \pm 0.71$ & 0.02 \\
\hline
\end{tabular}

Table 3: Main variables results. Statistically significant for $\mathrm{p}<0.05$; SD: Standard Deviation. 
Citation: Azzolini C, Donati S, Caprani SM, Gandolfi C, Vinciguerra R, et al. (2014) Macular Edema and Silicone Oil Tamponade. J Clin Exp Ophthalmol 5: 366. doi:/10.4172/2155-9570.1000366

Page 5 of 8

Figures 2 and 3 show the correlation between the studied variables and the presence and entity of macular edema. We valued the correlation for each association. In particular (Figure 2a-b) we show a significative correlation between macular edema and the macular status before surgery (on vs off; r: 0.48). Likewise (Figure 3) we analyze the correlation between intraocular silicone oil permanence and the entity of macular edema ( $\mathrm{r}$ : 0.52), visual acuity after silicone oil removal ( $r$ : -0.55$)$ and the type of macular edema ( $r: 0.45)$.
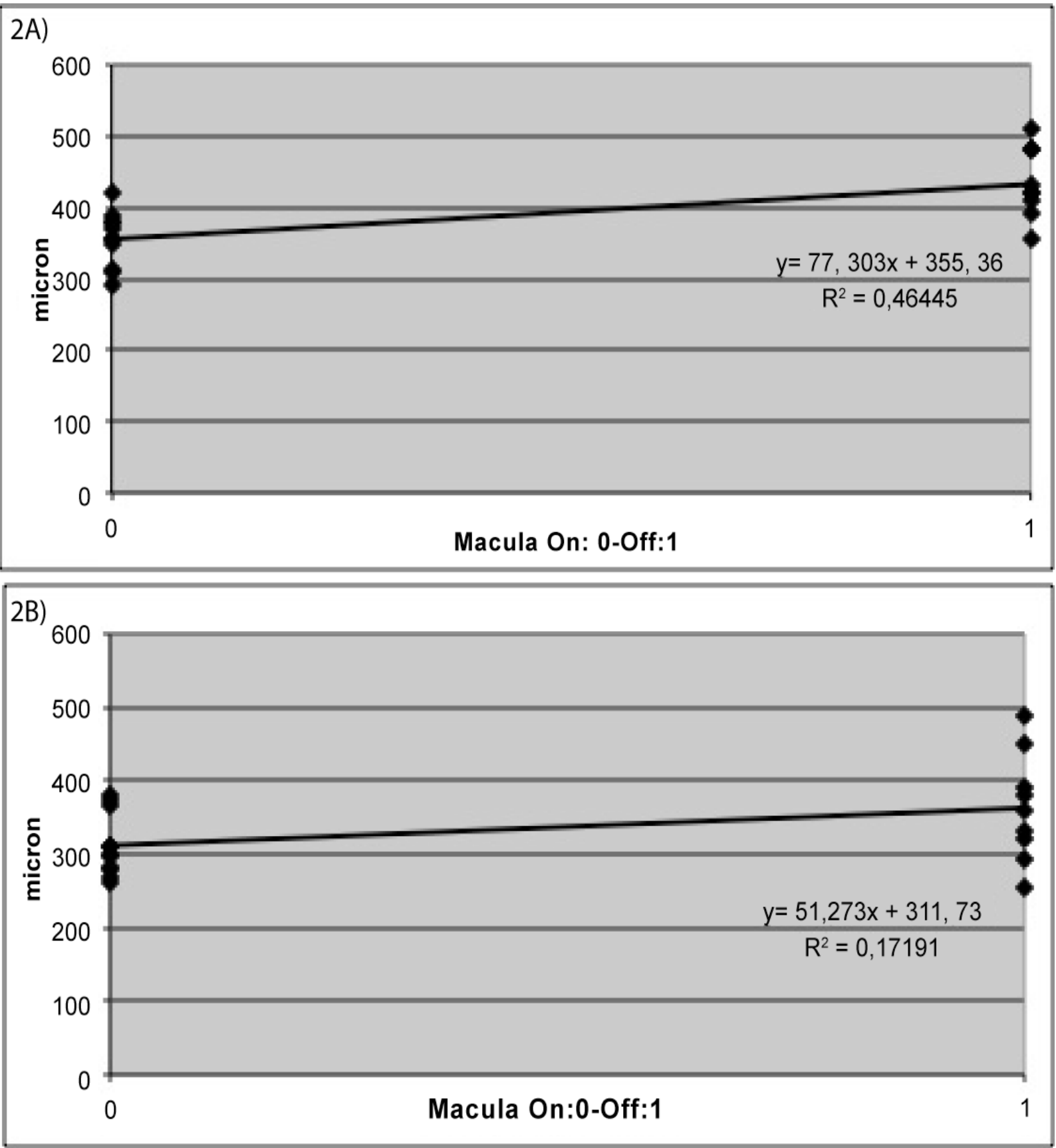

Figure 2: Graphic representation of correlation between preoperative macular status (macula on: 0; macula off: 1) and macular edema: a) at month 1 with intraocular SO (r: 0.68); b) at month 1 after surgery for SO removal ( $\mathrm{r}: 0.41)$. Dots represent each eye data, continuous line represents the statistical tendency. The equation defines the statistical correlation. 

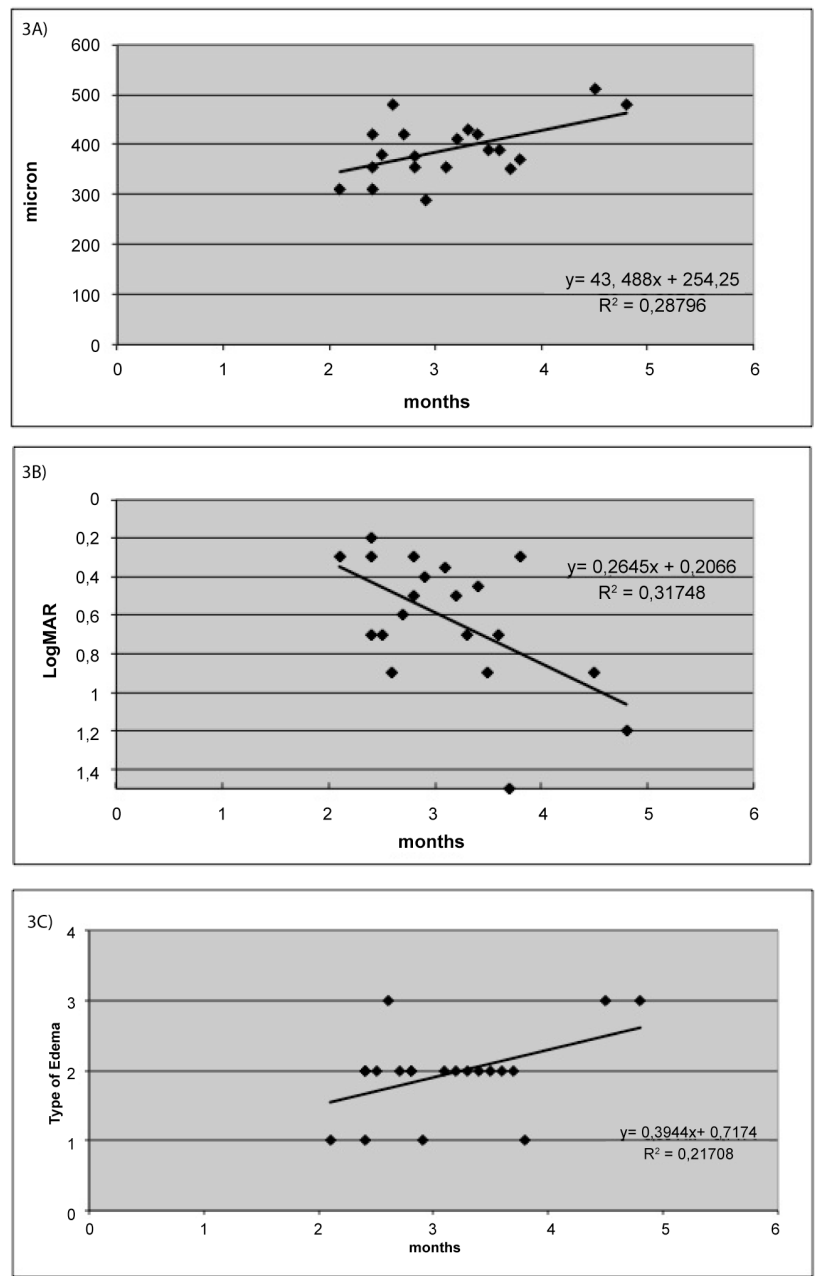

Figure 3: SO permanence and macular edema. a) correlation between time of SO permanence and Macular Thickness ( $\mathrm{r}: 0.53$ ); b) correlation between time of SO permanence and Visual Acuity (r: 0.56); c) correlation between time of SO permanence and type of macular edema:- 0: Normal Macula; 1: Mild Edema $<350 \mu \mathrm{m}$ Thickness; 2: Medium Edema Between 350-450 $\mu \mathrm{m}$; 3: Severe Edema $>450 \mu \mathrm{m}$ (r: 0.41). Dots represent each eye data, continuous line represents the statistical tendency. The equation defines the statistical correlation.

Figures 4 and 5 shows the progression of macular thickness and visual acuity during follow-up on studied patients.

\section{Discussion}

In a normal macula, hydrostatic pressure forcing fluids from the vessel into the tissue is balanced by osmotic pressure, which is generated by the colloidal protein solution in the capillary, forcing fluid absorption from the tissue $[1,3]$. This balance was not present in 20 out of 92 (22\%) of our patients with SO 1000cs filled eyes, despite successful surgery to reattach the retina. We found varying amounts of ME during SO permanence inside the eye, and at 1 and 6 months after its removal.

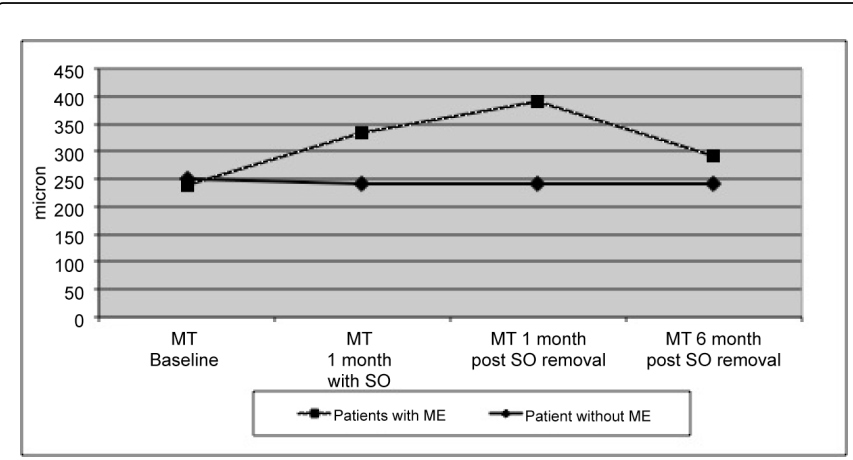

Figure 4: Macular edema variations in studied eyes during follow up.

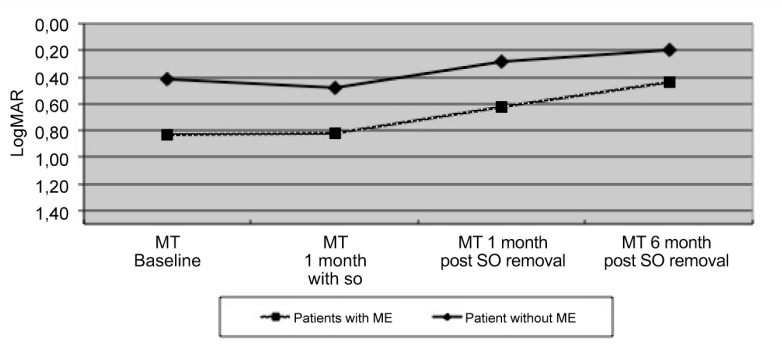

Figure 5: Visual Acuity variation in studied eyes during follow up.

The importance of patient age for postoperative visual recovery is controversial [26-29]. According to some authors, incomplete visual recovery following surgery for retinal detachment might be linked to age. Our study didn't find any significant correlation with macular edema.

Correlation was found between preoperative macula-off and ME during SO intraocular permanence and one month after SO removal (Figure 2). Macular neuroepithelium detachment might cause retinal cell degeneration right from the first weeks. It has already been underlined that the height of macular detachment can hinder visual recovery [26,30,31]. In macular-off retinal detachment, the diffusion of nutritive products from the choroid through the subretinal fluid could theoretically only be possible in shallow macular detachment.

Correlation was found between ME and SO permanence inside the eye (Figure 3). Several factors may be involved in the pathogenesis of macular edema in SO filled eyes. Molecular transport by diffusion or convention is inversely related to the viscosity of the medium. When the vitreous gel is replaced with less viscous saline liquid, transport of all molecules is facilitated. When the vitreous gel is replaced by silicone oil, which is more viscous than vitreous gel, transport of all molecules is slowed down, reducing transport in the vitreous cavity of molecules such as oxygen and other nutrients, growth factors, and cytokines. Reduced oxygenation from the anterior eye concentration increases the stimulus for edema formation as oxygen is a major regulator of hypoxia-induced growth factors and exerts an influence on capillary leakage $[1,26]$. It has also been reported that some growth factors and inflammatory factors related to vascular permeability 
might be concentrated into a smaller volume between SO and the retina $[17,32-34]$.

Using gas chromatography, it was shown that SO contains lowmolecular-weight components that seem to decline while the oil is in the vitreous cavity. Thus, low-molecular-weight components presumably diffuse from the oil into the ocular tissue causing inflammation and chronic ocular toxicity with secondary $\mathrm{ME}$ $[23,24,35]$.

Other studies underline the failure of potassium siphoning by Muller cells. Due to the displacement of vitreous fluid, intraretinal accumulation of potassium occurs leading to subsequent neuronal degeneration. Early retinal thinning detected by OCT occurs secondary to ganglion cell and inner plexiform layers [19,22].

Furthermore, the dynamics of the silicone oil-macular interface during the post-operative period have not been fully understood. In a series of a surgically treated macular hole cases using SO, the vitreous tamponade provides a mechanical "flotation force" at its apex against the macular region while patients are face-down [36]. In our cases, a floating silicone oil bubble could be responsible for macula inflammation and secondary ME, especially in dynamic patients, or patients that move a lot while sleeping.

Finally, a combination of vitreous substitutes with ocular media forms sequences of spectral filters in the eye, and this may modify retinal irradiation using either coherent or incoherent light. Lights of shorter wavelengths-UV and near the UV portion of the spectrum-are more dangerous, as they have more energy per photon than light with longer wavelengths. A healthy vitreous body partially absorbs ultraviolet light up to 315 , while all SOs absorbs only up to 250, leaving the UV-B wavelength to reach the retina. Transmission of incoherent light through highly transparent silicone oils may in time lead to dangerous light exposure, particularly in aphakic eyes that lack UV-A and UV-B lens absorption properties. Intraoperative light can induce retinal injury called photic retinopathy that causes inflammation and ME [37,38].

SO removal is indicated when the retina is completely attached, without new epiretinal membranes or when parts of the retina are detached but relegated to the periphery by retinopexy. Cryo or laser retinopexy are definitely effective after a few weeks. In these cases, there is no reason not to remove SO after 4-5 weeks. In other cases, some surgeons prefer to observe the possible re-growth of retinal membranes. In addition, in other cases SO removal is delayed for organizational reasons. Our results suggest the removal of $\mathrm{SO}$ as soon as possible to avoid ME occurring during SO tamponade. Early removal of SO helps avoid possible toxic effects, floating SO bubble on the macula and secondary inflammation, and to normalize the redistribution of oxygen and all inflammatory factors in the vitreous cavity.

Various experiences with early and long-term therapy have been described in the literature $[39,40]$. Topical non-steroidal antiinflammatory drugs, topical steroids, parabulbar injections etc. show variable efficacy depending on the entity of the edema and the duration of the therapy. We listed the therapies carried out on our patients, but we did not find any interesting data regarding significance and correlation.

This study has some limitations. We only considered the main variables on macular edema formation and its influence on visual acuity. Many other variables could be considered only with larger groups of patients to avoid a risk of bias.

Furthermore, the presence of previous unknown macular diseases could influence the results. Also cataract surgery could have an impact on macular edema and visual acuity: we performed cataract surgery only in 2 patients, due to the increased opacity affecting the correct fundus exploration and OCT macular investigation; the surgery has been performed only after silicone oil removal, and so this event didn't affect statistical analysis.

Finally, despite that the surgical technique employed was standard, as often happens in vitreoretinal surgery, alternative maneuvers could be carried out on each patient that might influence the final results.

In conclusion, we found correlation between ME in SO-filled eyes with preoperative macula-off retinal detachment and with the permanence of SO inside the eye. The pathogenetic mechanism of ME is not clear, and several factors are thought to be involved. Decreased transport of oxygen and other molecules in the vitreous space, together with the permanence of inflammatory substances between SO and the macula, could be involved in the pathogenesis of $\mathrm{ME}$. Moreover, physical factors such as the mechanical floating of SO and dangerous light exposure could play an important role. We found correlation between $\mathrm{SO}$ and the permanence of SO oil inside the eye, and $\mathrm{SO}$ should therefore be removed as soon as possible.

\section{Acknowledgement}

The Authors wish to thank Michael John of the Vita-Salute San Raffaele University in Milan for the English language editing of this paper.

\section{References}

1. Stefánsson E (2009) Physiology of vitreous surgery. Graefes Arch Clin Exp Ophthalmol 247: 147-163.

2. Tranos PG Wickremasinghe SS, Stangos NT, Topouzis F, Tsinopoulos I, et al. (2004) Macular edema. Surv Ophthalmol 49: 470-490.

3. Scholl S Kirchhof J, Augustin AJ (2010) Pathophysiology of macular edema. Ophthalmologica 224 Suppl 1: 8-15.

4. Scholl S Augustin A, Loewenstein A, Rizzo S, Kupperman B (2011) General pathophysiology of macular edema. Eur J Ophthalmol 21 Suppl 6: S10-19.

5. Hunter A Chin EK, Telander DG (2013) Macular edema in the era of spectral-domain optical coherence tomography. Clin Ophthalmol 7: 2085-2089.

6. Ossewaarde-van Norel A, Rothova A (2012) Imaging methods for inflammatory macular edema. Int Ophthalmol Clin 52: 55-66.

7. Azzolini C Sansoni G, Donati S, Parodi MB, Al Oum M, et al. (2013) Clinical analysis of macular edema with new software for SD-OCT imaging. Eur J Ophthalmol 23: 899-904.

8. Laqua H Lucke K, Foerster MH (1988) [Development and current status of silicone oil surgery]. Klin Monbl Augenheilkd 192: 277-283.

9. Riedel KG Gabel VP, Neubauer L, Kampik A, Lund OE (1990) Intravitreal silicone oil injection: complications and treatment of 415 consecutive patients. Graefes Arch Clin Exp Ophthalmol 228: 19-23.

10. [No authors listed] (1992) Vitrectomy with silicone oil or perfluoropropane gas in eyes with severe proliferative vitreoretinopathy: results of a randomized clinical trial. Silicone Study Report 2. Arch Ophthalmol 110: 780-792

11. [No authors listed] (1992) Vitrectomy with silicone oil or sulfur hexafluoride gas in eyes with severe proliferative vitreoretinopathy: results of a randomized clinical trial. Silicone Study Report 1. Arch Ophthalmol 110: 770-779. 
12. Casswell AG Gregor ZJ (1987) Silicone oil removal. I. The effect on the complications of silicone oil. Br J Ophthalmol 71: 893-897.

13. Franks WA Leaver PK (1991) Removal of silicone oil--rewards and penalties. Eye (Lond) $5: 333-337$.

14. Larkin GB Flaxel CJ, Leaver PK (1998) Phacoemulsification and silicone oil removal through a single corneal incision. Ophthalmology 105: 2023-2027.

15. Hutton WL Azen SP, Blumenkranz MS, Lai MY, McCuen BW, et al. (1994) The effects of silicone oil removal. Silicone Study Report 6. Arch Ophthalmol 112: 778-785.

16. Grzybowski A Pieczynski J, Ascaso FJ (2014) Neuronal complications of intravitreal silicone oil: an updated review. Acta Ophthalmol 92: 201-204.

17. Bae SH, Hwang JS, Yu HG (2012) Comparative analysis of macular microstructure by spectral-domain optical coherence tomography before and after silicone oil removal. Retina 32:1874-1883.

18. Romano V Angi M, Scotti F, del Grosso R, Romano D, et al. (2013) Inflammation and macular oedema after pars plana vitrectomy. Mediators Inflamm 2013: 971758.

19. Newsom RS Johnston R, Sullivan PM, Aylward GB, Holder GE, et al. (2004) Sudden visual loss after removal of silicone oil. Retina 24: 871-877.

20. Kim SW Oh J, Yang KS, Kim MJ, Rhim JW, et al. (2010) Risk factors for the development of transient hypotony after silicone oil removal. Retina 30: 1228-1236.

21. Caramoy A Droege KM, Kirchhof B, Fauser S (2014) Retinal layers measurements in healthy eyes and in eyes receiving silicone oil-based endotamponade. Acta Ophthalmol 92: e292-297.

22. Winter M Eberhardt W, Scholz C, Reichenbach A (2000) Failure of potassium siphoning by Müller cells: a new hypothesis of perfluorocarbon liquid-induced retinopathy. Invest Ophthalmol Vis Sci 41: $256-261$

23. Gabel VP, Kampik A, Burkhardt J (1987) Analysis of intraocularly applied silicone oils of various origins. Graefes Arch Clin Exp Ophthalmol 225: 160-162.

24. Gabel VP, Kampik A, Gabel C, Spiegel D (1987) Silicone oil with high specific gravity for intraocular use. Br J Ophthalmol 71: 262-267.

25. Gonvers M, Hornung JP, de Courten C (1986) The effect of liquid silicone on the rabbit retina. Histologic and ultrastructural study. Arch Ophthalmol 104: 1057-1062.

26. Abouzeid H Wolfensberger TJ (2006) Macular recovery after retinal detachment. Acta Ophthalmol Scand 84: 597-605.

27. Hagimura N Suto K, Iida T, Kishi S (2000) Optical coherence tomography of the neurosensory retina in rhegmatogenous retinal detachment. Am J Ophthalmol 129: 186-190.
28. Wolfensberger TJ Gonvers M (2002) Optical coherence tomography in the evaluation of incomplete visual acuity recovery after macula-off retinal detachments. Graefes Arch Clin Exp Ophthalmol 240: 85-89.

29. Lecleire-Collet A, Muraine M, Menard JF, Brasseur G (2005) Predictive visual outcome after macula-off retinal detachment surgery using optical coherence tomography. Retina 25:44-53.

30. Mervin K, Valter K, Maslim J, Lewis G, Fisher S, et al (1999) Limiting photoreceptor death and deconstruction during experimental retinal detachment: the value of oxygen supplementation. Am J Ophthalmol 128:155-164.

31. Sakai T Lewis GP, Linberg KA, Fisher SK (2001) The ability of hyperoxia to limit the effects of experimental detachment in cone-dominated retina. Invest Ophthalmol Vis Sci 42: 3264-3273.

32. Mukai N, Lee PF, Oguri M, Schepens CL (1975) A long-term evaluation of silicone retinopathy in monkeys. Can J Ophthalmol 10: 391-402.

33. Mukai N, Lee PF, Schepens CL (1972) Intravitreous injection of silicone: an experimental study. II. Histochemistry and electron microscopy. Ann Ophthalmol 4: 273-287.

34. Asaria RH Kon CH, Bunce C, Sethi CS, Limb GA, et al. (2004) Silicone oil concentrates fibrogenic growth factors in the retro-oil fluid. $\mathrm{Br} \mathrm{J}$ Ophthalmol 88: 1439-1442.

35. Nakamura K Refojo MF, Crabtree DV, Pastor J, Leong FL (1991) Ocular toxicity of low-molecular-weight components of silicone and fluorosilicone oils. Invest Ophthalmol Vis Sci 32: 3007-3020.

36. Oster SF Mojana F, Bartsch DU, Goldbaum M, Freeman WR (2010) Dynamics of the macular hole-silicone oil tamponade interface with patient positioning as imaged by spectral domain-optical coherence tomography. Retina 30: 924-929.

37. Azzolini C Docchio F, Brancato R, Trabucchi G (1992) Interactions between light and vitreous fluid substitutes. Arch Ophthalmol 110: 1468-1471.

38. Azzolini C Brancato R, Venturi G, Bandello F, Pece A, et al. (1994) Updating on intraoperative light-induced retinal injury. Int Ophthalmol 18: 269-276.

39. Rothova A (2002) Medical treatment of cystoid macular edema. Ocul Immunol Inflamm 10: 239-246.

40. Sanders DR, Kraff M (1984) Steroidal and nonsteroidal antiinflammatory agents. Effect on postsurgical inflammation and bloodaqueous humor barrier breakdown. Arch Ophthalmol 102: 1453-1456. 